\title{
Homogeneous precipitation synthesis and sintering behavior of microwave dielectrics: $\mathrm{Ba}\left(\mathrm{Mg}_{1 / 3} \mathrm{Ta}_{2 / 3}\right) \mathrm{O}_{3}$
}

\author{
Chung-Hsin Lu*, Chien-Cheng Tsai \\ Department of Chemical Engineering, National Taiwan University, Taipei, Taiwan, ROC
}

Received 18 December 1997

\begin{abstract}
Barium magnesium tantalate $\left(\mathrm{Ba}\left(\mathrm{Mg}_{1 / 3} \mathrm{Ta}_{2 / 3}\right) \mathrm{O}_{3}\right)$ has been successfully prepared by a new homogeneous precipitation process. The presence of chlorine species in the precipitates results in direct formation of $\mathrm{Ba}\left(\mathrm{Mg}_{1 / 3} \mathrm{Ta}_{2 / 3}\right) \mathrm{O}_{3}$ after $100^{\circ} \mathrm{C}$ drying, as well as rapid thermal expansion and cracking of specimens above $1300^{\circ} \mathrm{C}$. When chlorine species are completely removed from the precipitates, $\mathrm{Ba}\left(\mathrm{Mg}_{1 / 3} \mathrm{Ta}_{2 / 3}\right) \mathrm{O}_{3}$ starts to form from $600^{\circ} \mathrm{C}$, and the desired pure phase is achieved after $900^{\circ} \mathrm{C}$ calcination for $2 \mathrm{~h}$. With appropriate calcination followed by sintering at $1690^{\circ} \mathrm{C}$, densified crack-free $\mathrm{Ba}\left(\mathrm{Mg}_{1 / 3} \mathrm{Ta}_{2 / 3}\right) \mathrm{O}_{3}$ ceramics are achieved. In comparison with conventional solid state reactions, the new precipitation process developed here not only reduces the temperature of formation of superlattice structure, but also significantly increases the ordering parameter. This precipitation process is believed to be able to effectively suppress segregation of cations and enhance the compositional homogeneity of precursors, thereby facilitating an orderly arrangement of B-site cations in $\mathrm{Ba}\left(\mathrm{Mg}_{1 / 3} \mathrm{Ta}_{2 / 3}\right) \mathrm{O}_{3}$. C) 1998 Elsevier Science S.A. All rights reserved.
\end{abstract}

Keywords: $\mathrm{Ba}\left(\mathrm{Mg}_{1 / 3} \mathrm{Ta}_{2 / 3}\right) \mathrm{O}_{3}$; Preparation; Precipitation; Powder

\section{Introduction}

Due to the incessantly increasing demands of miniaturizing the important passive microwave components, such as dielectric resonators and frequency filters, intensive researches have focused on development of highly dielectric ceramics [1]. In this regard, the complex perovskite ceramics $\left(\mathrm{A}\left(\mathrm{B}_{1 / 3}^{\prime} \mathrm{B}_{2 / 3}^{\prime \prime}\right) \mathrm{O}_{3}\right)$ have attracted much attention because they exhibit excellent dielectric properties at microwave frequencies, such as high dielectric constant $(\kappa)$, high dielectric quality factor $(Q)$, and low resonant frequency temperature coefficient $\left(\tau_{\mathrm{f}}\right)$ [2-7]. Among all the complex perovskite compounds, barium magnesium tantalate $\left(\mathrm{Ba}\left(\mathrm{Mg}_{1 / 3} \mathrm{Ta}_{2 / 3}\right) \mathrm{O}_{3}\right)$ has been found to possess the highest $Q$ value [8]. The crystal structure of this material transforms from cubic perovskite-type into trigonal symmetry with 1:2 B-site ordering at elevated temperatures [9].

Although $\mathrm{Ba}\left(\mathrm{Mg}_{1 / 3} \mathrm{Ta}_{2 / 3}\right) \mathrm{O}_{3}$ possesses excellent properties for microwave applications, it is hardly sintered, even at extremely high temperatures. Therefore, in or-

\footnotetext{
* Corresponding author. Tel.: +886 2 3635230; fax: +8862 3623040 .
}

der to enhance the sinterability of $\mathrm{Ba}\left(\mathrm{Mg}_{1 / 3} \mathrm{Ta}_{2 / 3}\right) \mathrm{O}_{3}$, appropriate dopants have been added; however, such additions might deteriorate the microwave characteristics of $\mathrm{Ba}\left(\mathrm{Mg}_{1 / 3} \mathrm{Ta}_{2 / 3}\right) \mathrm{O}_{3}$ [2,3]. The solution synthesis processes have also been regarded as other alternatives for improving the characteristics of powders. For example, the semi-precipitation method [10] and the sol-gel process using alkoxides or inorganic salts [11-16] as raw materials have been used to prepare pure $\mathrm{Ba}\left(\mathrm{Mg}_{1 / 3}\right.$ $\left.\mathrm{Ta}_{2 / 3}\right) \mathrm{O}_{3}$. In the former process [10], magnesium and tantalum cations are precipitated by using oxine, and then the precipitates are subsequently mixed with $\mathrm{BaCO}_{3}$. Due to the insufficient mixing between precipitates and $\mathrm{BaCO}_{3}$, the synthesis temperature has to be raised to as high as $1300^{\circ} \mathrm{C}$ for complete generation of $\mathrm{Ba}\left(\mathrm{Mg}_{1 / 3} \mathrm{Ta}_{2 / 3}\right) \mathrm{O}_{3}$. Heating at such high temperatures tends to cause grain growth in the powders, which is detrimental for sintering. On the other hand, the solgel process, using alkoxides, can effectively reduce the formation temperature and facilitate sintering [11-15]; however, the stringent operation conditions involved due to the high sensitivity of alkoxides to moisture, as well as the high cost of alkoxides, limit usage of this process in industry. When inorganic salts are used in 
the sol-gel process [16], the consequent presence of polymers tends to retard the decomposition of $\mathrm{BaCO}_{3}$, thus increasing the temperature for synthesizing $\mathrm{Ba}\left(\mathrm{Mg}_{1 / 3} \mathrm{Ta}_{2 / 3}\right) \mathrm{O}_{3}$.

In general, the $Q$ value of $\mathrm{Ba}\left(\mathrm{Mg}_{1 / 3} \mathrm{Ta}_{2 / 3}\right) \mathrm{O}_{3}$ significantly depends on the compositional purity, sintering density, and the degree of ordering of magnesium and tantalum cations locating in B-sites. For obtaining densified monophasic $\mathrm{Ba}\left(\mathrm{Mg}_{1 / 3} \mathrm{Ta}_{2 / 3}\right) \mathrm{O}_{3}$ ceramics with highly ordered structure from inexpensive raw materials, a new homogeneous precipitation process has been developed in this study. This process involves simultaneous precipitation of the constitute cations to overcome the insufficient mixing of cations, which occurs in the semi-precipitation process [10]. The formation processes of $\mathrm{Ba}\left(\mathrm{Mg}_{1 / 3} \mathrm{Ta}_{2 / 3}\right) \mathrm{O}_{3}$ in the thus obtained precipitates have been studied and the calcination conditions are accordingly adjusted to yield monophasic powders. The influence of residual chlorine species present in precipitates on formation and sintering of $\mathrm{Ba}\left(\mathrm{Mg}_{1 / 3} \mathrm{Ta}_{2 / 3}\right) \mathrm{O}_{3}$ is investigated. Furthermore, the effects of calcination conditions on the sintering density and superlattice structure are also examined.

\section{Experimental}

The cation solutions were prepared from reagent grade $\mathrm{Ba}\left(\mathrm{NO}_{3}\right)_{2}, \mathrm{Mg}\left(\mathrm{NO}_{3}\right)_{2}$ and $\mathrm{TaCl}_{5}$. When $\mathrm{TaCl}_{5}$ was dissolved in water, precipitates of tantalum hydroxide were formed immediately; therefore, water was considered to be an inappropriate solvent for preparing a clear solution of tantalum cations. In addition, consid-

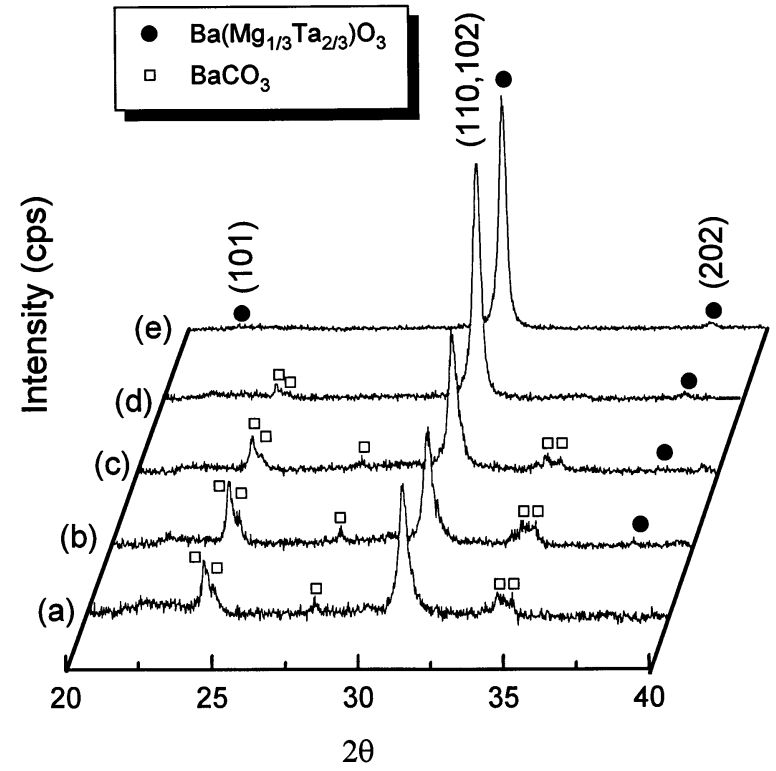

Fig. 1. X-ray diffraction patterns of (a) as-dried $\mathrm{Ba}\left(\mathrm{Mg}_{1 / 3} \mathrm{Ta}_{2 / 3}\right) \mathrm{O}_{3}$ precipitates and samples quenched at (b) $175^{\circ} \mathrm{C}$, (c) $400^{\circ} \mathrm{C}$, (d) $720^{\circ} \mathrm{C}$ and (e) $900^{\circ} \mathrm{C}$.

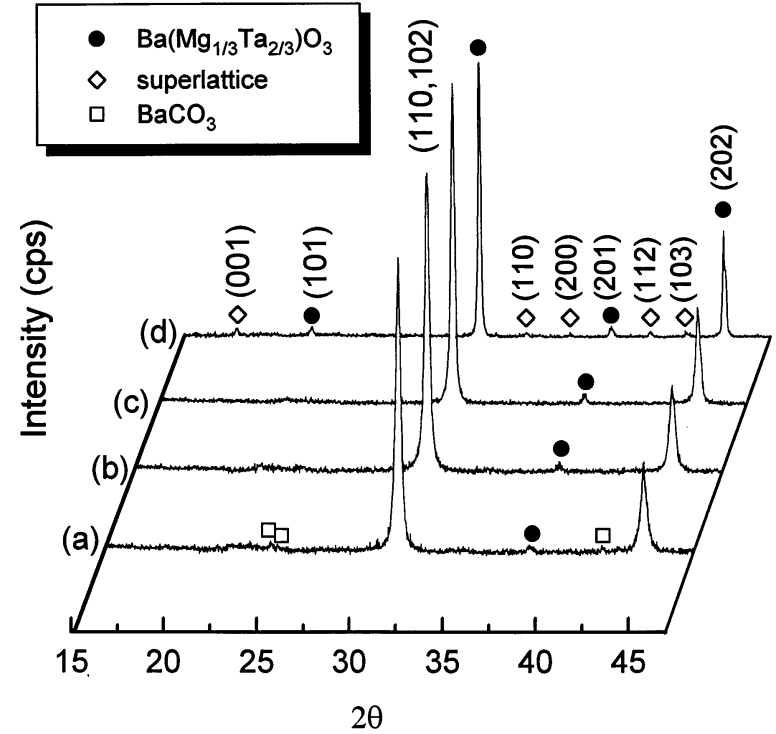

Fig. 2. X-ray diffraction patterns of $\mathrm{Ba}\left(\mathrm{Mg}_{1 / 3} \mathrm{Ta}_{2 / 3}\right) \mathrm{O}_{3}$ precipitates calcined at (a) $800^{\circ} \mathrm{C}$, (b) $900^{\circ} \mathrm{C}$, (c) $1100^{\circ} \mathrm{C}$ and (d) $1300^{\circ} \mathrm{C}$ in process I.

ering that both tantalum and magnesium cations are situated at $\mathrm{B}$-sites in $\mathrm{Ba}\left(\mathrm{Mg}_{1 / 3} \mathrm{Ta}_{2 / 3}\right) \mathrm{O}_{3}, \mathrm{TaCl}_{5}$ was dissolved in ethanol and mixed with $\mathrm{Mg}\left(\mathrm{NO}_{3}\right)_{2}$ in ethanol solution at a molar ratio of $\mathrm{Mg}^{2+}: \mathrm{Ta}^{5+}=1: 2$, in order to enhance the compositional homogeneity of cations at B-sites. This solution was then mixed with $\mathrm{Ba}\left(\mathrm{NO}_{3}\right)_{2}$ aqueous solution with stoichiometric amount of barium cations. Tetramethylammonium hydroxide was then added to this solution under rapid stirring to convert all cations into hydroxide precipitates. For preparing dried powders, two different routes were utilized. In process

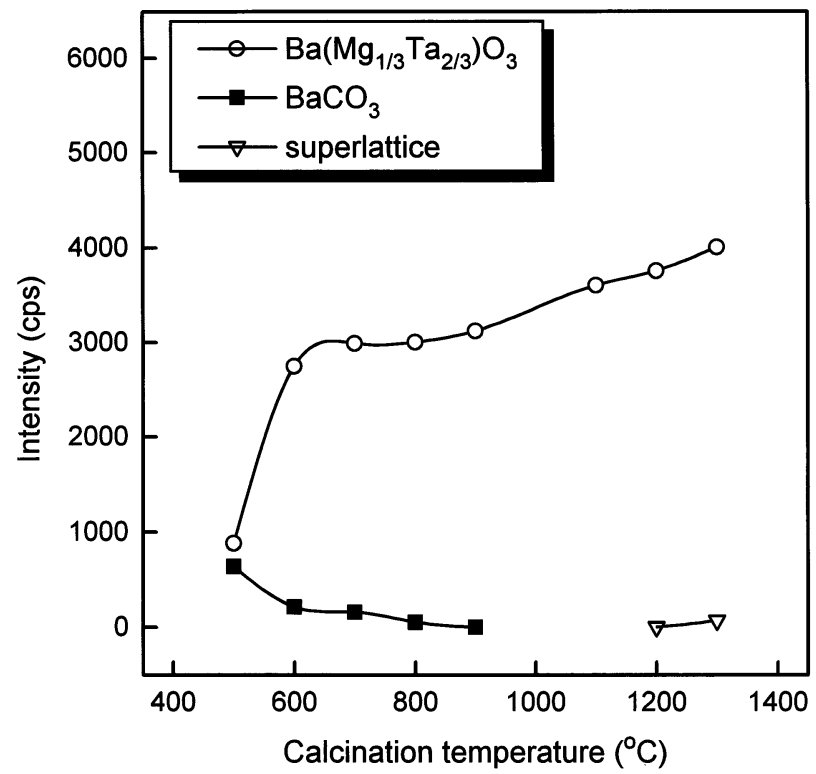

Fig. 3. X-ray diffraction intensity of resultant compounds vs. calcination temperature for the precipitates of $\mathrm{Ba}\left(\mathrm{Mg}_{1 / 3} \mathrm{Ta}_{2 / 3}\right) \mathrm{O}_{3}$ derived from process I. 

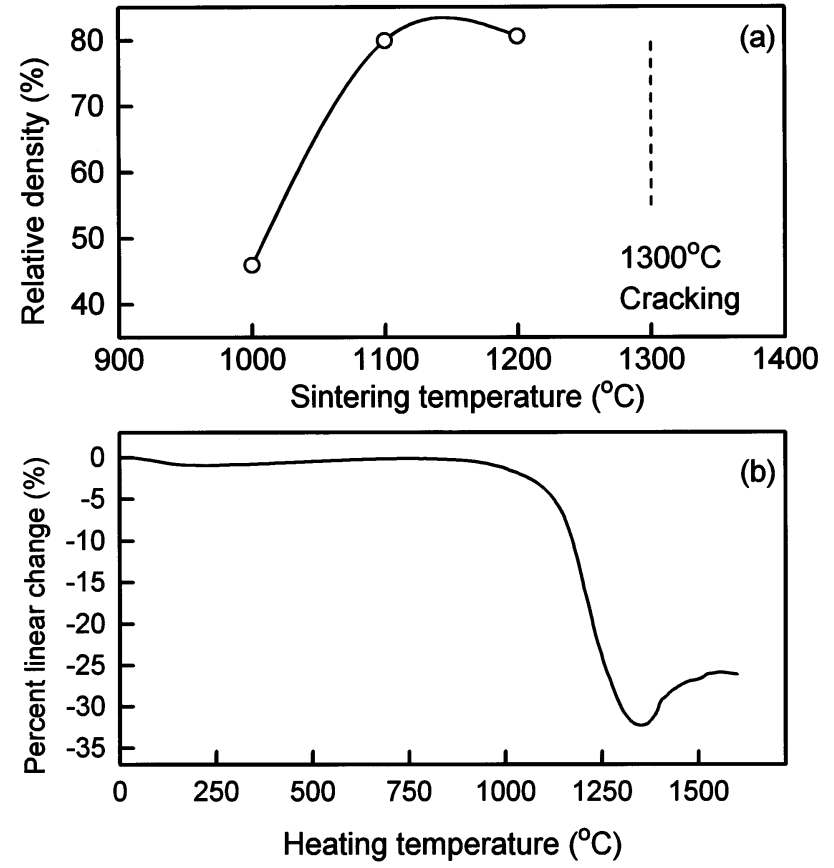

Fig. 4. (a) Sintering density of $\mathrm{Ba}\left(\mathrm{Mg}_{1 / 3} \mathrm{Ta}_{2 / 3}\right) \mathrm{O}_{3}$ powders derived from process I vs. sintering temperature. (b) Shrinkage behavior of $\mathrm{Ba}\left(\mathrm{Mg}_{1 / 3} \mathrm{Ta}_{2 / 3}\right) \mathrm{O}_{3}$ prepared by process $\mathrm{I}$.

I, the precipitates were dried at $100^{\circ} \mathrm{C}$, and washed with deionized water to remove the residual chlorine ions. In process II, the precipitates were first washed with deionized water for several times prior to drying at $100^{\circ} \mathrm{C}$. Consequently, the powders of $\mathrm{Ba}\left(\mathrm{Mg}_{1 / 3} \mathrm{Ta}_{2 / 3}\right) \mathrm{O}_{3}$ precursors were obtained. The particle size of the obtained powders was measured

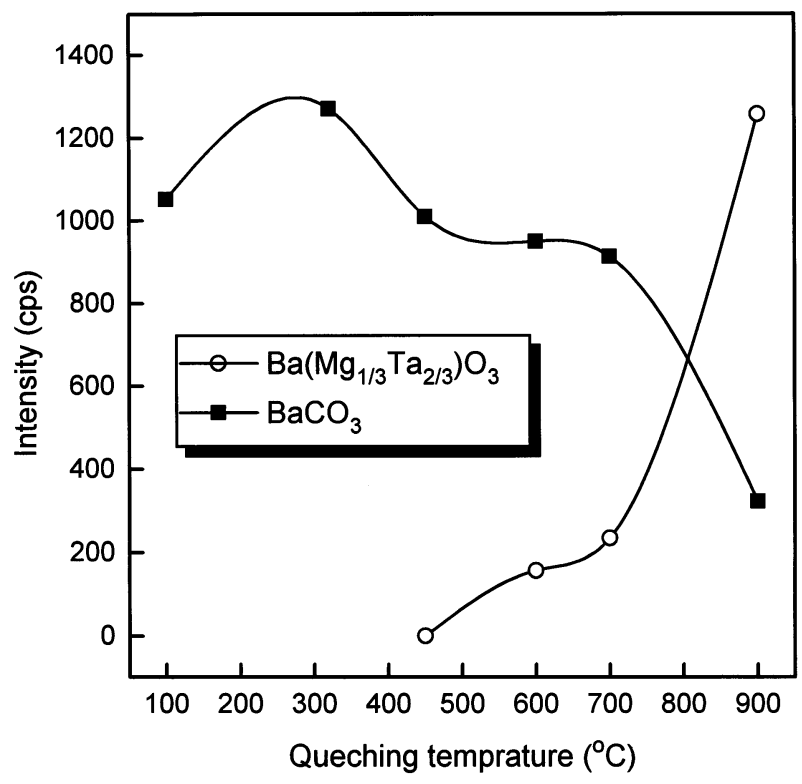

Fig. 5. X-ray diffraction intensity of resultant compounds vs. quenching temperature for the precipitates of $\mathrm{Ba}\left(\mathrm{Mg}_{1 / 3} \mathrm{Ta}_{2 / 3}\right) \mathrm{O}_{3}$ prepared by process II

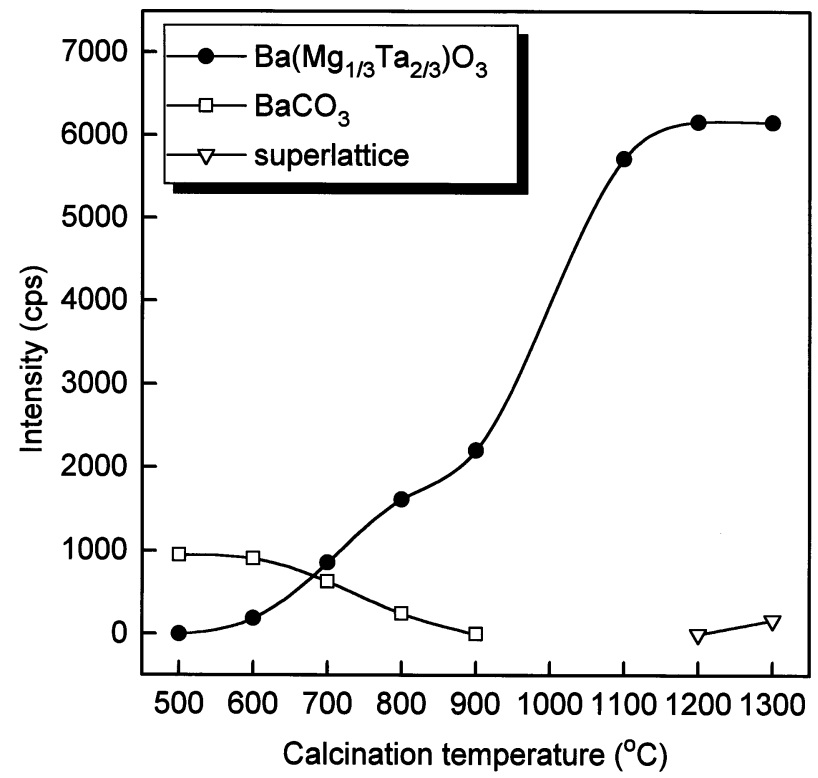

Fig. 6. X-ray diffraction intensity of resultant compounds vs. calcination temperature for the precipitates of $\mathrm{Ba}\left(\mathrm{Mg}_{1 / 3} \mathrm{Ta}_{2 / 3}\right) \mathrm{O}_{3}$ prepared by process II.

by SEM and found to be $\approx 0.3 \mu \mathrm{m}$.

For studying the variation in the resultant compounds, the as-dried precipitates prepared by processes I and II were heated and rapidly quenched in air during the heating processes. The compounds present in these quenched specimens were identified by X-ray powder diffraction (XRD) analysis. Thermogravimetry analysis
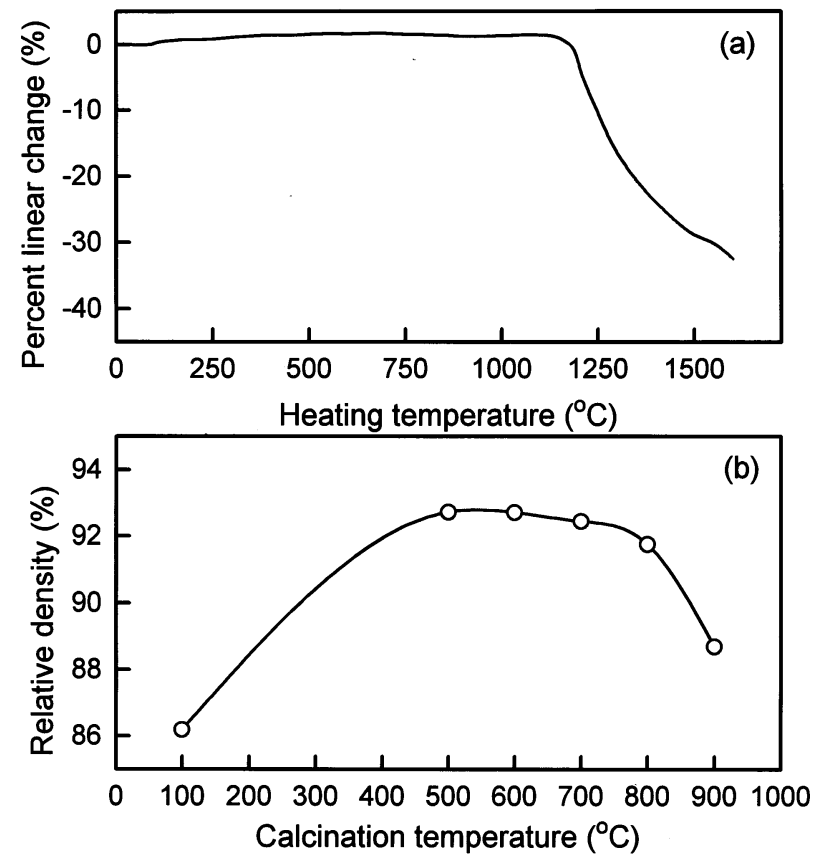

Fig. 7. (a) Shrinkage behavior of $\mathrm{Ba}\left(\mathrm{Mg}_{1 / 3} \mathrm{Ta}_{2 / 3}\right) \mathrm{O}_{3}$ prepared by process II. (b) Sintering density of $\mathrm{Ba}\left(\mathrm{Mg}_{1 / 3} \mathrm{Ta}_{2 / 3}\right) \mathrm{O}_{3}$ prepared by process II vs. calcination temperature after sintering at $1690{ }^{\circ} \mathrm{C}$ for 2 h. 


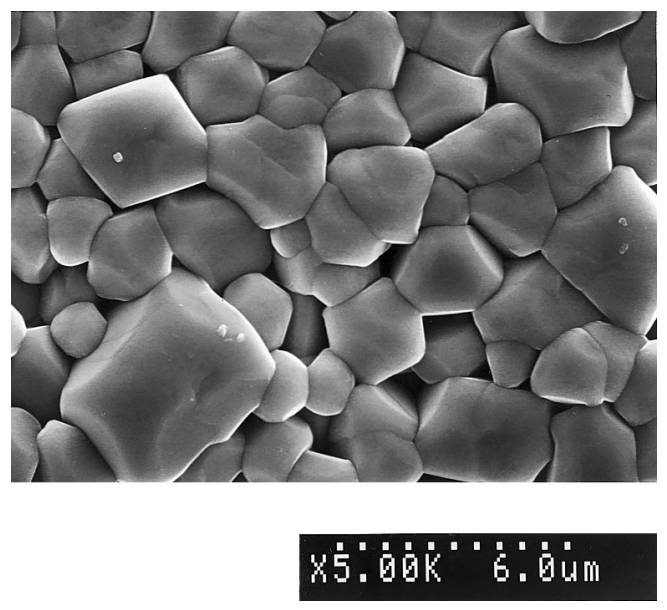

Fig. 8. SEM micrograph of $700^{\circ} \mathrm{C}$ calcined $\mathrm{Ba}\left(\mathrm{Mg}_{1 / 3} \mathrm{Ta}_{2 / 3}\right) \mathrm{O}_{3}$ sintered at $1690^{\circ} \mathrm{C}$ for $2 \mathrm{~h}$.

(TGA) was conducted to detect the thermal variations and weight changes of the precursors. A dilatometer was used to examine the shrinkage behavior of the pressed pellets. For obtaining pure $\mathrm{Ba}\left(\mathrm{Mg}_{1 / 3} \mathrm{Ta}_{2 / 3}\right) \mathrm{O}_{3}$ powder, the precipitates were calcined for $2 \mathrm{~h}$ at temperatures ranging from 500 to $1300^{\circ} \mathrm{C}$. These calcined powders were ground and uniaxially die-pressed at 196 $\mathrm{MPa}$, and sintered in air at $1690^{\circ} \mathrm{C}$ for $2 \mathrm{~h}$. After sintering, the density of the sintered compacts and ordering parameter were measured, and the evolution of microstructures in the specimens were studied by scanning electron microscopy (SEM).

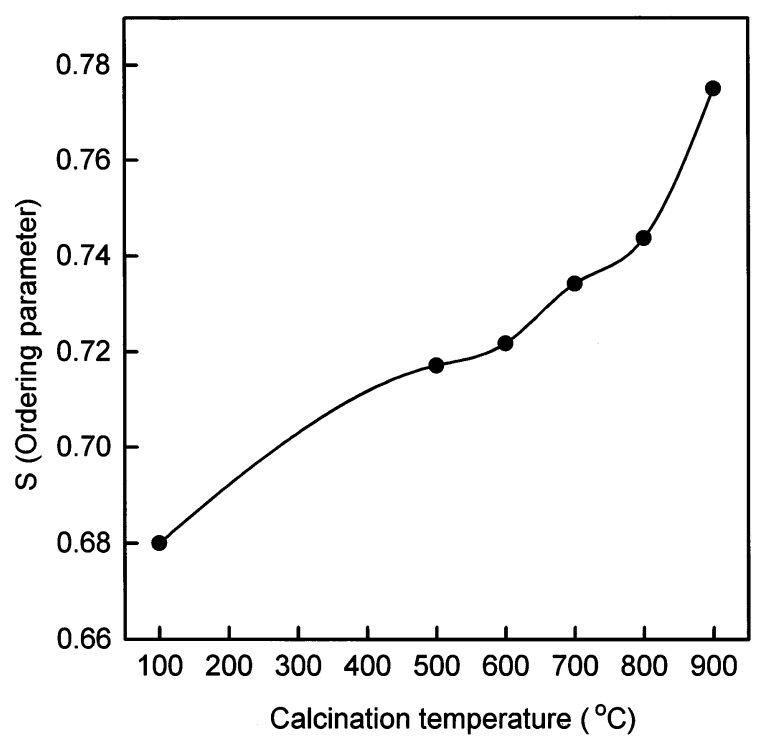

Fig. 9. Ordering parameter of sintered $\mathrm{Ba}\left(\mathrm{Mg}_{1 / 3} \mathrm{Ta}_{2 / 3}\right) \mathrm{O}_{3}$ prepared by process II vs. calcination temperature. Sintering condition: $1690^{\circ} \mathrm{C}$ for $2 \mathrm{~h}$.

\section{Results and discussion}

\subsection{Preparation of $\mathrm{Ba}\left(\mathrm{Mg}_{1 / 3} \mathrm{Ta}_{2 / 3}\right) \mathrm{O}_{3}$ by process $I$}

A series of precipitated precursors prepared by process I were quenched in air during heating, the XRD patterns of which are presented in Fig. 1. This figure reveals that the as-dried precipitates consist of $\mathrm{BaCO}_{3}$ and a small amount of $\mathrm{Ba}\left(\mathrm{Mg}_{1 / 3} \mathrm{Ta}_{2 / 3}\right) \mathrm{O}_{3}$ having cubic perovskite structure. This result indicates that $\mathrm{Ba}\left(\mathrm{Mg}_{1 /}\right.$ $\left.3 \mathrm{Ta}_{2 / 3}\right) \mathrm{O}_{3}$ begins to form after drying at $100^{\circ} \mathrm{C}$. With an increase in heating temperature, the amount of $\mathrm{Ba}\left(\mathrm{Mg}_{1 /}\right.$ $\left.3 \mathrm{Ta}_{2 / 3}\right) \mathrm{O}_{3}$ increases, accompanied by a corresponding decrease in the amount of $\mathrm{BaCO}_{3}$. After heating at $900^{\circ} \mathrm{C}$, all $\mathrm{BaCO}_{3}$ disappears, and only $\mathrm{Ba}\left(\mathrm{Mg}_{1 / 3} \mathrm{Ta}_{2 /}\right.$ $3 \mathrm{O}_{3}$ is in the product. When the as-dried precipitates were examined by TGA, a large weight loss of $\approx 27 \%$ occurred between 100 and $300^{\circ} \mathrm{C}$. This weight loss is attributed to the desorption of water from powders and thermal decomposition of hydroxides. When heating above $400^{\circ} \mathrm{C}$, the weight of specimens decreased progressively up to $900^{\circ} \mathrm{C}$, due to departure of $\mathrm{CO}_{2}$ from $\mathrm{BaCO}_{3}$ in the process of formation of $\mathrm{Ba}\left(\mathrm{Mg}_{1 / 3} \mathrm{Ta}_{2 /}\right.$ 3) $\mathrm{O}_{3}$.

For increasing the crystallinity of $\mathrm{Ba}\left(\mathrm{Mg}_{1 / 3} \mathrm{Ta}_{2 / 3}\right) \mathrm{O}_{3}$ powders, the precipitates were calcined at elevated temperatures. Fig. 2 presents the representative XRD patterns of the calcined specimens, while the variation in XRD intensity of compounds present in the products versus calcination temperature is plotted in Fig. 3. As can be seen from Figs. 2 and 3, the amount of $\mathrm{Ba}$ $\left(\mathrm{Mg}_{1 / 3} \mathrm{Ta}_{2 / 3}\right) \mathrm{O}_{3}$ increases rapidly with an increase in calcination temperature, and only a small amount of $\mathrm{BaCO}_{3}$ remains in the specimens after $800^{\circ} \mathrm{C}$ calcination. Raising the calcination temperature up to $900^{\circ} \mathrm{C}$ results in the complete formation of $\mathrm{Ba}\left(\mathrm{Mg}_{1 / 3} \mathrm{Ta}_{2 / 3}\right) \mathrm{O}_{3}$. The XRD pattern of $\mathrm{Ba}\left(\mathrm{Mg}_{1 / 3} \mathrm{Ta}_{2 / 3}\right) \mathrm{O}_{3}$ thus obtained, is consistent with that reported in JCPDS No. 8-212, confirming that pure $\mathrm{Ba}\left(\mathrm{Mg}_{1 / 3} \mathrm{Ta}_{2 / 3}\right) \mathrm{O}_{3}$ powder is obtained by the precipitation process. A further increase in calcination temperature improves crystallinity of $\mathrm{Ba}\left(\mathrm{Mg}_{1 / 3} \mathrm{Ta}_{2 / 3}\right) \mathrm{O}_{3}$. In addition, after calcination at $1300^{\circ} \mathrm{C}$, the diffraction peaks associated with the superlattice structure of $\mathrm{Ba}\left(\mathrm{Mg}_{1 / 3} \mathrm{Ta}_{2 / 3}\right) \mathrm{O}_{3}$ also appear. In comparison with the previously reported semi-precipitation [10] and sol-gel processes using inorganic salts [16], the precipitation process developed in this study significantly lowers the required temperature for preparation of monophasic $\mathrm{Ba}\left(\mathrm{Mg}_{1 / 3} \mathrm{Ta}_{2 / 3}\right) \mathrm{O}_{3}$ to $900^{\circ} \mathrm{C}$. This achievement in reducing the synthesis temperature for $\mathrm{Ba}\left(\mathrm{Mg}_{1 / 3} \mathrm{Ta}_{2 / 3}\right) \mathrm{O}_{3}$ is believed to result from the improvement in overall mixing homogeneity of cations and enhanced reactivity of starting materials.

Following calcination at $300^{\circ} \mathrm{C}$, the calcined powders were pressed and sintered at elevated temperatures. The relationship between density and sintering temperature 


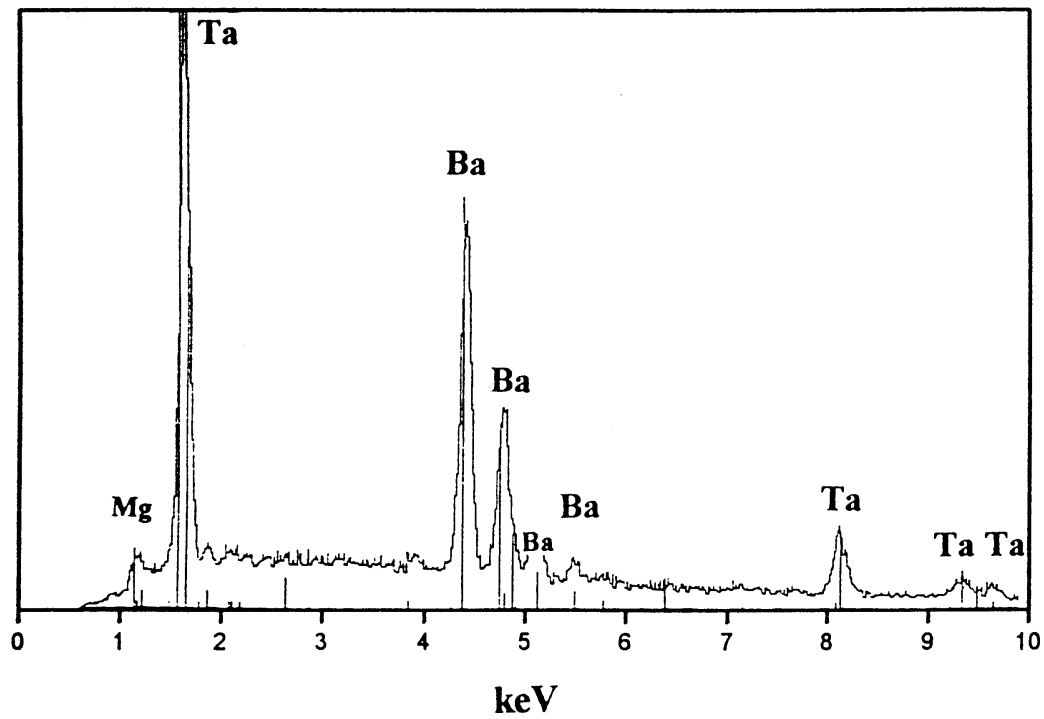

Fig. 10. Energy dispersive X-ray spectra of $\mathrm{Ba}\left(\mathrm{Mg}_{1 / 3} \mathrm{Ta}_{2 / 3}\right) \mathrm{O}_{3}$ prepared by process II.

is illustrated in Fig. 4(a). After sintering at $1200^{\circ} \mathrm{C}$, the relative density of specimens increases to $81 \%$. However, raising the temperature to $1300^{\circ} \mathrm{C}$ causes cracking of the specimens. In order to investigate that cracking phenomena, the shrinkage behavior of pressed pellets was examined by using a dilatometer, and the result is shown in Fig. 4(b). The specimen starts shrinking from $\approx 1000^{\circ} \mathrm{C}$, and shrinks rapidly with increasing temperature. Nevertheless, from $\approx 1300^{\circ} \mathrm{C}$, the shrinkage of the specimen ceases, and abnormal expansion occurs, implying that vaporization of some species occurs at elevated temperatures. In order to further analyze the composition of the precipitates, an inductively coupled plasma spectrometer (ICP) was used. The ICP results revealed that besides the constitute species $\mathrm{Ba}, \mathrm{Mg}$ and $\mathrm{Ta}$, the precipitates also consisted of a small amount of chlorine (around $0.14 \mathrm{wt} . \%$ ). Therefore, cracking and abnormal expansion of specimens at elevated temperatures are believed to result from the vaporization of residual chlorine species present in the precipitates. The presence of chorine in specimens indicates that the washing process is not complete in process I.

\subsection{Preparation of $\mathrm{Ba}\left(\mathrm{Mg}_{1 / 3} \mathrm{Ta}_{2 / 3}\right) \mathrm{O}_{3}$ by process II}

In order to completely remove the chlorine species from the precipitated powders, the washing process was modified in process II. After the precipitates were formed, they were first washed with deionized water for several times, and then dried at $100^{\circ} \mathrm{C}$. The washed filtrate was examined by adding silver nitrate to ensure that no chlorine remained in the filtrate. When these as-dried precipitates were analyzed by ICP, no chlorine species were detected. This confirms that removal of chlorine species from the precipitates was complete in process II.
The precipitates thus obtained were heated and quenched at elevated temperatures. The XRD analysis of these specimens shows that only $\mathrm{BaCO}_{3}$ is present in the as-dried precipitates, and no $\mathrm{Ba}\left(\mathrm{Mg}_{1 / 3} \mathrm{Ta}_{2 / 3}\right) \mathrm{O}_{3}$ is formed. The relationship between the resultant compounds and quenching temperature is shown in Fig. 5. This figure indicates that formation of $\mathrm{Ba}\left(\mathrm{Mg}_{1 / 3} \mathrm{Ta}_{2 / 3}\right)$ $\mathrm{O}_{3}$ begins at $600^{\circ} \mathrm{C}$, and its amount rapidly increases with temperature increase. For preparing pure $\mathrm{Ba}\left(\mathrm{Mg}_{1 / 3}\right.$ $\left.\mathrm{Ta}_{2 / 3}\right) \mathrm{O}_{3}$, the precipitates were also calcined at various temperatures for $2 \mathrm{~h}$. As shown in Fig. 6, calcination at $900^{\circ} \mathrm{C}$ results in complete formation of $\mathrm{Ba}\left(\mathrm{Mg}_{1 / 3} \mathrm{Ta}_{2 / 3}\right)$ $\mathrm{O}_{3}$. In addition, the superlattice structure of $\mathrm{Ba}\left(\mathrm{Mg}_{1 / 3}\right.$ $\left.\mathrm{Ta}_{2 / 3}\right) \mathrm{O}_{3}$ begins to appear at $1300^{\circ} \mathrm{C}$. Compared with the solid state reaction [17], the present precipitation process reduces the temperature for occurrence of superlattice structure from 1400 to $1300^{\circ} \mathrm{C}$. Based on the results described in Section 3.1 and this section, it is confirmed that both precipitation processes I and II yield monophasic $\mathrm{Ba}\left(\mathrm{Mg}_{1 / 3} \mathrm{Ta}_{2 / 3}\right) \mathrm{O}_{3}$ powders. It is also noted that when the precipitates are dried at $100^{\circ} \mathrm{C}$, $\mathrm{Ba}\left(\mathrm{Mg}_{1 / 3} \mathrm{Ta}_{2 / 3}\right) \mathrm{O}_{3}$ starts to form in process $\mathrm{I}$, but not in process II. The presence of residual chlorine species in the precipitates in process I seems to accelerate the kinetics of formation of $\mathrm{Ba}\left(\mathrm{Mg}_{1 / 3} \mathrm{Ta}_{2 / 3}\right) \mathrm{O}_{3}$. In the hydrothermal synthesis of $\mathrm{BaTiO}_{3}$, chlorine ions have been also found to play an important role on the crystallization processes of powders [18].

\subsection{Sintering and superlattice structure of $\mathrm{Ba}\left(\mathrm{Mg}_{1 / 3} \mathrm{Ta}_{2 / 3}\right) \mathrm{O}_{3}$ in process II}

The shrinkage behavior of the as-dried precipitates prepared by process II is illustrated in Fig. 7(a). This specimen rapidly shrinks from above $1150^{\circ} \mathrm{C}$ up to $1600^{\circ} \mathrm{C}$. No abnormal thermal expansion, similar to 
that found in process I, is observed at elevated temperatures. This result reveals that the complete removal of chlorine species from the precipitates did indeed prevent abnormal expansion of the specimens. Following calcination at various temperatures, the as-dried and calcined powders were pressed and sintered at $1690^{\circ} \mathrm{C}$ for $2 \mathrm{~h}$. Fig. 7(b) shows the relationship between the density of sintered specimens and calcination temperature. When the as-dried precipitates were directly sintered at $1690^{\circ} \mathrm{C}$, their relative density of specimens was only $86 \%$. This low density is due to the removal of $\mathrm{CO}_{2}$ from unreacted $\mathrm{BaCO}_{3}$, that causes expansion and de-sintering of the specimens. As the calcination temperature increased to $500-700^{\circ} \mathrm{C}$, densified $\mathrm{Ba}\left(\mathrm{Mg}_{1 / 3}\right.$ $\left.\mathrm{Ta}_{2 / 3}\right) \mathrm{O}_{3}$ ceramics without cracking were obtained, and the density of sintered $\mathrm{Ba}\left(\mathrm{Mg}_{1 / 3} \mathrm{Ta}_{2 / 3}\right) \mathrm{O}_{3}$ reached a plateau ( $\approx 93 \%$ ). However, further increase in calcination temperature to $800^{\circ} \mathrm{C}$ and higher caused a reduction in the density. Similar effects of calcination temperature on density have also been found in solgel-derived $\mathrm{Ba}\left(\mathrm{Mg}_{1 / 3} \mathrm{Ta}_{2 / 3}\right) \mathrm{O}_{3}[15,16]$. This adverse effect of increasing calcination temperature on the density is attributed to a reduction in sintering ability of powders after over-calcined processes. SEM examination of the samples indicated that the sintered $\mathrm{Ba}\left(\mathrm{Mg}_{1 / 3} \mathrm{Ta}_{2 / 3}\right) \mathrm{O}_{3}$ exhibited uniform microstructures, and no abnormal grains due to the deficiency in barium content were observed [17]. The representative microstructure of sintered $\mathrm{Ba}\left(\mathrm{Mg}_{1 / 3} \mathrm{Ta}_{2 / 3}\right) \mathrm{O}_{3}$ obtained from $700^{\circ} \mathrm{C}$ calcined powders is shown in Fig. 8. The calcination temperature was found to influence the porosity of specimens, but did not significantly affect the grain size, which was $\approx 2-3 \mu \mathrm{m}$.

After sintering at $1690^{\circ} \mathrm{C}$, all of the above specimens exhibited superlattice structure, implying that the crystalline structure of $\mathrm{Ba}\left(\mathrm{Mg}_{1 / 3} \mathrm{Ta}_{2 / 3}\right) \mathrm{O}_{3}$ transformed from a random state into a partially ordered state with $\mathrm{Mg}^{2+}$ and $\mathrm{Ta}^{5+}$ ordering at B-sites. For characterizing the ordering parameter $(S)$ of these sintered specimens, an equation derived from a crystallographic view was used [17]. The equation used is expressed as

$S=(46.9 Y /(3.82-Y))^{1 / 2}$

where $Y$ is equal to the value of $I_{100} /\left(I_{110}+I_{102}+I_{012}\right)$ of the sintered specimens, and $I_{100}$ and $I_{110}+I_{102}+I_{012}$ represent the diffraction intensity of the major reflections in the superlattice and the fundamental disordered structure, respectively. As can be seen from Fig. 9, the ordering parameter monotonously increases from 0.68 to 0.775 as the calcination temperature is increased from 100 to $900^{\circ} \mathrm{C}$. This result indicates that the increase in calcination temperature has a pronounced effect on enhancing the ordering degree of $\mathrm{Ba}\left(\mathrm{Mg}_{1 / 3}\right.$ $\left.\mathrm{Ta}_{2 / 3}\right) \mathrm{O}_{3}$. When a similar sintering process was applied to the powders prepared by conventional solid state reaction, the ordering parameter was only 0.61 [17], which is much lower than that obtained by the present precipitation process. The $\mathrm{Ba}\left(\mathrm{Mg}_{1 / 3} \mathrm{Ta}_{2 / 3}\right) \mathrm{O}_{3}$ powders prepared by both solid state reaction and precipitation process (process II) were further analyzed by EDS. The typical EDS spectra of $\mathrm{Ba}\left(\mathrm{Mg}_{1 / 3} \mathrm{Ta}_{2 / 3}\right) \mathrm{O}_{3}$ prepared by the precipitation process are shown in Fig. 10. It was found that the fluctuations in composition were markedly reduced in the precipitation derived powders. Therefore, the obtained enhancement in the ordering parameter in the $\mathrm{Ba}\left(\mathrm{Mg}_{1 / 3} \mathrm{Ta}_{2 / 3}\right) \mathrm{O}_{3}$ obtained by the precipitation process is attributed to the improvement in the compositional homogeneity of cations in these powders achieved by the precipitation process, which promotes an orderly arrangement of cations at B-sites in $\mathrm{Ba}\left(\mathrm{Mg}_{1 / 3} \mathrm{Ta}_{2 / 3}\right) \mathrm{O}_{3}$.

\section{Conclusions}

The new homogeneous precipitation process developed here successfully yields monophasic $\mathrm{Ba}\left(\mathrm{Mg}_{1 / 3}\right.$ $\left.\mathrm{Ta}_{2 / 3}\right) \mathrm{O}_{3}$. When chlorine species are present in the precipitates, $\mathrm{Ba}\left(\mathrm{Mg}_{1 / 3} \mathrm{Ta}_{2 / 3}\right) \mathrm{O}_{3}$ is formed after $100^{\circ} \mathrm{C}$ drying. The presence of chlorine ions also results in cracking of the specimens at $1300^{\circ} \mathrm{C}$. After complete removal of chlorine species from the precipitates, the formation of $\mathrm{Ba}\left(\mathrm{Mg}_{1 / 3} \mathrm{Ta}_{2 / 3}\right) \mathrm{O}_{3}$ starts from $600^{\circ} \mathrm{C}$, and is accomplished at $900^{\circ} \mathrm{C}$. This obtained powder provides densified crack-free ceramics after sintering at $1690^{\circ} \mathrm{C}$. The sintered $\mathrm{Ba}\left(\mathrm{Mg}_{1 / 3} \mathrm{Ta}_{2 / 3}\right) \mathrm{O}_{3}$ has a higher ordering parameter than that prepared by conventional solid state reaction. The increase in the ordering parameter is attributed to enhancement in the compositional homogeneity of precursors prepared by the precipitation process.

\section{Acknowledgements}

The authors would like to thank the National Science Council, Taiwan, ROC, for financial support of this study under Contract No. NSC 83-0405-E002-012.

\section{References}

[1] W. Wersing, Electronic Ceramics, Elsevier Applied Science, Amsterdam, 1991, p. 67.

[2] S. Nomura, K. Toyama, K. Kaneta, Jpn. J. Appl. Phys. 21 (1982) L624.

[3] S. Kawashima, M. Nishida, I. Ueda, H. Ouchi, J. Am. Ceram. Soc. 66 (1983) 421.

[4] S.B. Desu, H.M. O’Bryan, J. Am. Ceram. Soc. 68 (1985) 546.

[5] K. Endo, K. Fujimoto, K. Murakawa, J. Am. Ceram. Soc. 70 (1987) C215.

[6] K.H. Yoon, B.J. Jung, E.S. Kim, J. Mater. Sci. Lett. 8 (1989) 819. 
[7] H. Matsumoto, H. Tamura, K. Wakino, Jpn. J. Appl. Phys. 30 (1991) 2347.

[8] H.J. Youn, K.K. Kim, H. Kim, Jpn. J. Appl. Phys. 35 (1996) 3947.

[9] D.J. Barber, K.M. Moulding, J. Zhou, M. Li, J. Mater. Sci. 32 (1997) 1531.

[10] K. Kakegawa, T. Wakabayashi, Y. Sasaki, J. Am. Ceram. Soc. 69 (1986) 82.

[11] T. Fukni, C. Sakurai, M. Okuyama, J. Mater. Res. 7 (1992) 1883.
[12] S. Katsyama, M. Sekine, J. Mater. Chem. 2 (1992) 889.

[13] O. Renoult, J.P. Boilot, F. Chaput, R. Papiernik, L.G. HubertPfalzgraf, M. Lejeune, J. Am. Ceram. Soc. 75 (1992) 3337.

[14] D. Ravichandran, B. Jin, R. Roy, A.S. Bhalla, Mater. Lett. 25 (1995) 257.

[15] S. Katayama, I. Yoshinaga, N. Yamada, T. Nagai, J. Am. Ceram. Soc. 79 (1996) 2059.

[16] C.H. Lu, C.C. Tasi, Mater. Lett. 3 (1997) 271

[17] C.H. Lu, C.C. Tasi, J. Mater. Res. 11 (1996) 1219.

[18] P.K. Dutta, J.R. Gregg, Chem. Mater. 4 (1992) 843. 